\title{
Agrobacterium tumefaciens VirB11 Protein Requires a Consensus Nucleotide-Binding Site for Function in Virulence
}

\author{
KATHRYN M. STEPHENS, CHRISTINE ROUSH, $†$ AND EUGENE NESTER* \\ Department of Microbiology, University of Washington, Seattle, Washington 98195
}

Received 24 May 1994/Accepted 12 October 1994

\begin{abstract}
virB11, one of the 11 genes of the virB operon, is absolutely required for transport of T-DNA from Agrobacterium tumefaciens into plant cells. Previous studies reported that VirB11 is an ATPase with autophosphorylation activity and localizes to the inner membrane even though the protein does not contain the consensus N-terminal export sequence. In this report, we show that VirB11 localizes to the inner membrane even in the absence of other tumor-inducing (Ti) plasmid-encoded proteins. To facilitate the further characterization of VirB11, we purified this protein from the soluble fraction of an Escherichia coli extract by fusing VirB11 to the maltose-binding protein. The maltose-binding protein-VirB11 fusion was able to complement a virB11 deletion mutant of $A$. tumefaciens for tumor formation and also localized properly to the inner membrane of $A$. tumefaciens. The 72-kDa protein, purified from $E$. coli, exhibited no autophosphorylation, ATPase activity, or ATP-binding activity. To study the importance of the Walker nucleotide-binding site present in VirB11, mutations were generated to replace the conserved lysine residue with either alanine or arginine. Expression of the virB11K175A mutant gene resulted in an avirulent phenotype, and expression of the virB11K175R mutant gene gave rise to an attenuated virulence phenotype. Both mutant proteins were present at levels three to four times higher than that of VirB11 in the wild-type strain. The mutant genes did not exhibit a transdominant phenotype on tumor formation in bacteria that were expressing wild-type virB11. The mutant proteins also localized properly to the inner membrane of $A$. tumefaciens, but the VirB11K175R protein appeared to be unstable after lysis of the cells.
\end{abstract}

The soil bacterium Agrobacterium tumefaciens causes the plant disease crown gall. The bacteria can infect dicotyledonous plants at a wound site and induce the formation of tumors at the site of infection. Virulent strains of $A$. tumefaciens contain a large tumor-inducing (Ti) plasmid that carries the factors responsible for formation of the crown gall tumors. The bacteria have the unusual property of being able to transfer a segment of DNA (T-DNA) from the Ti plasmid into the host plant cells. The T-DNA is integrated into the plant genome, and expression of the oncogenes present in the T-DNA results in formation of the tumor (for recent reviews, see references 26, 70, and 73).

The genes required for the transfer of T-DNA into the recipient plant cells are divided into eight vir operons on the octopine-type Ti plasmid (54). These genes are expressed only when the bacteria are exposed to wounded plant cells as a result of the action of several plant signal molecules acting in concert with the virA and virG gene products. Once the vir genes have been expressed, the gene products act in a coordinated fashion to synthesize T-DNA strands and direct the transfer of the T-DNA into a recipient plant cell.

The T-DNA and associated proteins are transported through the bacterial inner and outer membranes and through the plant cell wall and plasma membrane into the cytoplasm. The 11 genes of the virB operon and virD4 are required for this transport step in the tumor formation process $(1,14)$. virD4 and the virB operon are not required for any of the early steps such as attachment, induction, or T-DNA processing but are

\footnotetext{
* Corresponding author. Mailing address: Department of Microbiology, SC-42, University of Washington, Seattle, WA 98195. Phone: (206) 543-5825. Fax: (206) 543-8297.

$\dagger$ Present address: Department of Plant Biology, University of Illinois, Urbana-Champaign, IL 61801.
}

absolutely essential for tumor formation $(7,20,51,54,66)$. VirD4, VirB1, VirB2, VirB3, VirB4, VirB5, VirB8, VirB9, VirB10, and VirB11 have all been localized to the membrane fraction by immunological techniques $(12,41,50,51,57,58$, $67)$. These proteins could form a pilus-like structure in the membrane that is similar to those involved in conjugation of plasmids between gram-negative bacteria $(26,72)$.

Recently, the operons required for pilin biogenesis and conjugation of the broad-host-range plasmids of RP4 (IncP group) and R388 (IncW group) have been sequenced $(26,74)$. The deduced amino acid sequences of 6 of the trb genes (IncP) and 10 of the trw genes (IncW) share significant sequence identity with the VirB proteins $(26,74)$. Not only are the virB genes similar in sequence to the conjugation genes, but they are also functionally similar. For example, $A$. tumefaciens can transfer the promiscuous IncQ plasmid RSF1010 into plant cells in a vir gene-dependent manner (8). Also, RSF1010 can inhibit TDNA transfer presumably by competition for the T-DNA transport apparatus, and this inhibition can be overcome by overexpressing virB9, virB10, and virB11 (64). Finally, induced $A$. tumefaciens can mediate transfer of the RSF1010 plasmid between agrobacteria in a virB- and virD4-dependent manner $(6,20)$.

It is becoming apparent that T-DNA transport may resemble protein secretion pathways as well. The genes required for secretion of Bordetella pertussis toxin, a large multisubunit complex, have been sequenced, and the predicted amino acid sequences of seven of these $p t l$ genes show significant sequence identity to virB gene products (68).

Two of the proteins in each of these systems contain putative nucleotide-binding sites (Walker boxes) $(12,26,65,68,74)$. The two potential nucleotide-binding proteins in the virB operon, VirB4 and VirB11, are both absolutely required for virulence $(7,20,51,54)$. Both proteins are also localized to the 
inner membrane of $A$. tumefaciens even though VirB11 does not contain an $\mathrm{N}$-terminal export sequence or long hydrophobic stretches of amino acids $(12,57,65)$. VirB4 localizes to the membrane fraction of induced $A$. tumefaciens even when the $\mathrm{Ti}$ plasmid is absent from the cell (7). Both VirB4 and VirB11 proteins, purified from Escherichia coli, have been reported to have weak ATPase activities in vitro $(12,51)$. Purified VirB11 protein also has been reported to have autophosphorylation activity in vitro (12).

VirB11 is a member of a large PulE-like protein family of potential nucleotide-binding proteins important for secretion in gram-negative bacteria (45). The genes for these proteins are present as part of large operons required for secretion. Members of this family include pulE, required for pullulanase secretion in Klebsiella oxytoca (43); outE, required for secretion of pectate lyases and cellulases in Erwinia chrysanthemi (35); $x c p R$, required for secretion of toxin A, lipases, and proteases in Pseudomonas aeruginosa (4); pilB, required for pilin biogenesis in $P$. aeruginosa (39); and $x p s E$, required for secretion of proteases and cellulases in Xanthomonas campestris (15). PulE protein has been localized to the membrane fraction in $E$. coli in the presence or the absence of the other pul genes even though it, like VirB11, lacks an N-terminal secretion signal (12, 43, 44). The nucleotide-binding site in the PulE-like family members is thought to be very important for their functions in their respective transport systems. These proteins are thought to either energize the secretion of the proteins out of the cells or activate the secretion apparatus (45).

Unlike the case of T-DNA transfer, the transport operons and their substrates are usually regulated only at the gene level (45). Once the transport apparatus and the substrate are synthesized in the cell, the substrate is transported in a constitutive manner (45). T-DNA transport is regulated at two levels. The vir genes are induced and T-DNA is processed when the bacteria are exposed to wound exudates, but T-DNA appears to be transported into the plant cell only after the bacteria have attached to the plant cell (10a). It is possible that one of the potential nucleotide-binding proteins VirB4 and VirB11 could be involved in this step in regulation of T-DNA transfer.

In this study, we explore the importance of the nucleotidebinding sequence in VirB11 for function in virulence of $A$. tumefaciens. Also, we have purified VirB11 protein as a fusion protein in an attempt to correlate in vitro activities of VirB11 to in vivo activities.

\section{MATERIALS AND METHODS}

Bacterial strains and plasmids. Table 1 lists the bacterial strains and plasmids used in this study. DNA was introduced into $A$. tumefaciens by triparental mating or electroporation using a Bio-Rad Laboratories electroporator (Richmond, Calif.) as described previously (9). E. coli was grown in Luria-Bertani (LB) medium and manipulated as described previously (47). A. tumefaciens was grown in $\mathrm{MG} / \mathrm{L}$ as described previously (9), or vir gene expression was induced by using the following modified procedure. Cells were grown to saturation in $\mathrm{MG} / \mathrm{L}$ broth in the presence of appropriate antibiotics, pelleted in a microcentrifuge for $2 \mathrm{~min}$ at room temperature, washed once with sterile $\mathrm{H}_{2} \mathrm{O}$, pelleted again, inoculated into a 10 -fold volume of modified induction broth [50 mM 2-( $N$-morpholino)ethanesulfonic acid (MES)-KOH (pH 5.5), AB salts (9), $0.02 \%$ yeast extract, $2 \%$ glucose, $200 \mu \mathrm{M}$ acetosyringone], and incubated with shaking for $16 \mathrm{~h}$ at $28^{\circ} \mathrm{C}$. This method resulted in a high yield of induced cells. Antibiotics were added as follows: carbenicillin, $100 \mu \mathrm{g} / \mathrm{ml}$; kanamycin, $100 \mu \mathrm{g} / \mathrm{ml}$; gentamicin, $50 \mu \mathrm{g} / \mathrm{ml}$; and tetracycline, $5 \mu \mathrm{g} / \mathrm{ml}$.

Reagents. Restriction endonucleases EcoRI and BamHI, anti-maltose-binding protein (MBP) antisera, and amylose resin were purchased from New England Biolabs, Beverly, Mass. All other restriction endonucleases, T4 DNA ligase, and T4 DNA polymerase were obtained from Bethesda Research Laboratories, Gaithersburg, Md. Anti-DnaK antisera was a generous gift of R. McMacken (Johns Hopkins University). Affi-Gel heparin gel was purchased from Bio-Rad Laboratories, Hercules, Calif. ${ }^{32}$ P-labeled ATP and GTP were obtained from Amersham Corp., Arlington Heights, Ill., and [ ${ }^{125}$ I]protein A was obtained from Dupont, NEN Research Products, Boston, Mass. Sequenase version 2.0 DNA sequencing kits were purchased from U.S. Biochemical Corp., Cleveland, Ohio. Centricon 10 microconcentrators were purchased from Amicon Corp., Beverly, Mass. $2^{\prime}-\left(3^{\prime}\right)-O$-(2,4,6-trinitrophenyl)adenosine-5' -triphosphate (TNP-ATP) was purchased from Molecular Probes, Inc., Eugene, Ore.

Construction of a $\Delta v \operatorname{irB11}$ strain of A. tumefaciens. The virB11 gene was deleted from pTiA6NC by the following procedure. The nptII gene with its promoter was excised from pKS17 (30) with SalI and ligated into the SalI site of pUC7 to generate pKS21. pJW322 was treated with Bam $\mathrm{HI}$ and $B g l \mathrm{II}$ to remove a 1-kb fragment containing the majority of virB11, and that fragment was replaced by a Bam HI fragment containing nptII and its promoter from pKS21, creating pKS29. pJW325 containing virB9 and virB10 was digested with EcoRI to remove a 2.1-kb fragment, which was then ligated into the EcoRI site of pKS29 to generate pKS30. pKS30 was introduced into strain A348 by electroporation, and mutants undergoing marker exchange were selected and analyzed as described previously (9). Strain A10011 was verified to contain nptII and its promoter in place of virB11 by analysis of Southern blots (data not shown) (53).

Cloning and expression of virB11 and malE-virB11 fusions in $E$. coli and $A$. tumefaciens. To purify VirB11 protein from E. coli, virB11 was fused to malE in the expression vector pMALc (36) by the following procedure. virB11 was removed from pJW322 by digestion with BamHI and HindIII. This fragment contains all of the virB11 coding sequence except that for the first four amino acids. The fragment was end filled with the large fragment of DNA polymerase I and then ligated to pMALc which had been restricted with StuI. This generated pKS27. The entire virB11 portion of this clone was sequenced to ensure that the fusion junction was correct and that no mutations had been introduced into the virB11 gene. To express malE and malE-virB11 in A. tumefaciens, pMALc and pKS27 were fused to the broad-host-range plasmid pUFR042 at unique EcoRI sites to create pKS73 and pKS40, respectively. The fusion genes remain under the transcriptional control of the tac promoter and lacI in these plasmids. These plasmids were introduced into A. tumefaciens A10011 ( $\Delta$ virB11). Native virB11 was expressed in $A$. tumefaciens from a plasmid in which pJW322 was fused to pED32 at unique EcoRI sites to place virB11 downstream of the virB promoter (pKS59) (20). To facilitate the cloning of mutant virB11 genes, pJW322 was cut with EcoRI and PstI, and a 1.4-kb fragment containing virB11 was ligated to pUC8 cut with EcoRI and PstI to generate pCR103.

Generation of mutations in the nucleotide-binding site of virB11. A 226-bp SphI-AccI fragment from pJW322, which encodes the consensus nucleotidebinding site ( ${ }^{169}$ Gly-Pro-Thr-Gly-Ser-Gly-Lys-Thr ${ }^{176}$ ), was ligated into SphI-AccI sites of pUC118 to create pCR100. pCR100 was introduced into CJ236, and single-stranded DNA templates were produced by superinfection with M13KO7 as described previously (62). The conserved lysine at position 175 was changed to either alanine (pCR101) or arginine (pCR102), using the procedure of Kunkel et al. (31), with the following oligonucleotides: 5'-GGAAGCGGCGCGACAAC AATGAGC-3', alanine at residue 175; and 5'-GGAAGCGGCAGGACAAC AATGAGC-3', arginine at residue 175. Plasmids were sequenced to screen for the desired mutations and to ensure that no other mutation was introduced into the 226-bp fragment. The wild-type $S p h \mathrm{I}-A c c \mathrm{I}$ fragment in pCR103 (virB11) was replaced with the $S p h \mathrm{I}-A c c \mathrm{I}$ fragment containing the alanine mutation (from pCR101) or the arginine mutation (from pCR102) to create pCR104 and pCR105, respectively. Three hundred base pairs of pCR104 and pCR105 were sequenced to confirm that the mutations were present and that no other changes were introduced during the cloning steps. pCR104 and pCR105 were fused to pED32 at the unique EcoRI sites with the mutant virB11 genes downstream of the virB promoter, which created pCR108 and pCR109, respectively.

Immunological techniques and subcellular fractionation. Proteins were separated by sodium dodecyl sulfate (SDS)-polyacrylamide gel electrophoresis (PAGE) (32) and detected by staining with Coomassie brilliant blue or by immunological analysis following transfer to nitrocellulose (59). The nitrocellulose filters were blocked with $5 \%$ nonfat milk in $50 \mathrm{mM}$ Tris- $\mathrm{HCl}(\mathrm{pH} 7.4)$ with $150 \mathrm{mM} \mathrm{NaCl}$ (Tris-buffered saline) and then incubated with appropriate antisera as previously described (12). After washing with Tris-buffered saline containing $0.1 \%$ Tween 20 , the blots either were developed with goat anti-rabbit antibody conjugated to alkaline phosphatase and detected with nitroblue tetrazolium and 5-bromo-4-chloro-3-indolyl phosphate (2) or were developed with ${ }^{125}$ I-labeled protein A.

Strains of $A$. tumefaciens were induced and analyzed for VirB11 protein by Western blot (immunoblot) analysis. Cells, equivalent to $1 \mathrm{ml}$ at an optical density at $600 \mathrm{~nm}\left(\mathrm{OD}_{600}\right)$ of 0.1 , were broken by boiling in sample buffer, and the proteins were separated electrophoretically on $12.5 \%$ acrylamide gels. Proteins blotted to nitrocellulose were probed with rabbit anti-VirB11 antisera (12) or rabbit anti-MBP antisera.

Subcellular fractionation was performed on 500-ml cultures of induced cells. Cells were collected by centrifugation, resuspended in $2 \mathrm{ml}$ of $50 \mathrm{mM} \mathrm{N}-2$ hydroxyethylpiperazine- $N$ '-2-ethanesulfonic acid (HEPES)-KOH (pH 7.8), and quickly frozen. The cells were thawed slowly on ice, brought to $0.2 \mathrm{mg}$ of lysozyme per $\mathrm{ml}$, and incubated for $30 \mathrm{~min}$ on ice. $\mathrm{MgCl}_{2}$ was added to $5 \mathrm{mM}$, RNase A was added to $100 \mu \mathrm{g} / \mathrm{ml}$, and DNase I was added to $12.5 \mu \mathrm{g} / \mathrm{ml}$. The cells were passaged twice through a French pressure cell, and cell debris was removed by centrifugation (11). The cell lysate was applied to discontinuous sucrose gradients and processed as previously described $(11,13)$. The fractions were analyzed to detect NADH oxidase, an inner membrane marker, and malate dehydrogenase, a cytoplasmic marker, by published procedures $(13,27)$. The 
TABLE 1. Bacterial strains and plasmids used

\begin{tabular}{|c|c|c|}
\hline $\begin{array}{l}\text { Bacterial strain } \\
\text { or plasmid }\end{array}$ & Relevant characteristics & Source or reference \\
\hline \multicolumn{3}{|l|}{ E. coli } \\
\hline DH5 $\alpha$ & supE44 $\Delta$ lacU169 ( $\$ 80$ lacZ $\Delta \mathrm{M} 15)$ hsdR17 recA1 endA1 gyrA96 thi-1 relA1 & Gibco-BRL \\
\hline CJ236 & dut1 ung1 thi1 relA/pCJ105(cam $\mathrm{F})$ & 31 \\
\hline \multicolumn{3}{|l|}{ A. tumefaciens } \\
\hline A136 & Strain C58 cured of pTi plasmid & 21 \\
\hline A348 & A136(pTiA6NC) & 21 \\
\hline A10011 & A348( $\Delta$ virB11) & This study \\
\hline \multicolumn{3}{|l|}{ Plasmids } \\
\hline pUC7 & $\mathrm{Carb}^{\mathrm{r}}$, cloning vector & 71 \\
\hline pUC8 & $\mathrm{Carb}^{\mathrm{r}}$, cloning vector & 71 \\
\hline pUC118 & $\mathrm{Carb}^{\mathrm{r}}$, cloning vector & 62 \\
\hline pUFR042 & $\operatorname{Kan}^{\mathrm{r}}, \mathrm{Gent}^{\mathrm{r}}$, broad-host-range IncW plasmid & 16 \\
\hline pIB100 & $\mathrm{Carb}^{\mathrm{r}}$, IncP plasmid containing virA and $\operatorname{vir} G$ genes & 3 \\
\hline pJW322 & $\mathrm{Carb}^{\mathrm{r}}, 1.4-\mathrm{kb}$ EcoRI-XhoI fragment containing virB11 in EcoRI-SalI sites of pUC118 & 12 \\
\hline pJW325 & $\begin{array}{l}\text { Carb }^{\mathrm{r}}, 3.5-\mathrm{kb} \text { EcoRI-XhoI fragment containing virB9, virB10, and virB11 in EcoRI-SalI sites of } \\
\text { pUC118 }\end{array}$ & 66 \\
\hline pMALc & $\mathrm{Carb}^{\mathrm{r}}$, MBP fusion vector & New England Biolabs \\
\hline pED32 & Tet $^{\mathrm{r}}$, broad-host-range IncP plasmid, virB promoter cassette & 66 \\
\hline pED11 & Tet $^{\mathrm{r}}$, pED32 containing virB11 downstream of the virB promoter & 66 \\
\hline pKS17 & $\mathrm{Carb}^{\mathrm{r}}, \mathrm{Kan}^{\mathrm{r}}$, nptII gene and promoter from Tn 5 inserted between virD2 and virD4 in pUC19 & 30 \\
\hline pKS21 & $\begin{array}{l}\mathrm{Carb}^{\mathrm{r}}, \mathrm{Kan}^{\mathrm{r}} \text {, 1-kb SalI fragment from pKS17 containing } n p t I I \text { gene and promoter into SalI sites } \\
\text { of pUC7 }\end{array}$ & This study \\
\hline pKS29 & $\begin{array}{l}\operatorname{Carb}^{\mathrm{r}}, \mathrm{Kan}^{\mathrm{r}}, 1-\mathrm{kb} \text { BamHI-BglII fragment of pJW322 replaced with 1-kb BamHI fragment of } \\
\text { pKS21 }\end{array}$ & This study \\
\hline pKS30 & $\begin{array}{l}\mathrm{Carb}^{\mathrm{r}}, \mathrm{Kan}^{\mathrm{r}}, 2.1-\mathrm{kb} \text { EcoRI fragment from pJW325 containing virB9 and virB10 cloned into } \\
\text { EcoRI site of pKS29 }\end{array}$ & This study \\
\hline pCR100 & $\mathrm{Carb}^{\mathrm{r}}, 226-\mathrm{bp} S p h \mathrm{I}-A c c \mathrm{I}$ fragment of $v i r B 11$ in $S p h \mathrm{I}-A c c \mathrm{I}$ sites of pUC118 & This study \\
\hline pCR101 & $\mathrm{Carb}^{\mathrm{r}}$, pCR100 with an Ala codon substitution for Lys-175 & This study \\
\hline pCR102 & $\mathrm{Carb}^{\mathrm{r}}$, pCR100 with an Arg codon substitution for Lys-175 & This study \\
\hline pCR103 & $\begin{array}{l}\mathrm{Carb}^{\mathrm{r}}, 1.4-\mathrm{kb} \text { EcoRI-Pst I fragment of pJW322 containing virB11 gene in EcoRI-PstI sites of } \\
\text { pUC8 }\end{array}$ & This study \\
\hline pCR104 & Carb $^{\mathrm{r}}$, pCR103 containing K175A mutation & This study \\
\hline pCR105 & $\mathrm{Carb}^{\mathrm{r}}$, pCR103 containing K175R mutation & This study \\
\hline pKS27 & $\begin{array}{l}\mathrm{Carb}^{\mathrm{r}}, 1.4-\mathrm{kb} \text { Bam HI-HindIII fragment from pJW322 end filled into StuI site of pMALc, virB11 } \\
\text { gene fused to malE }\end{array}$ & This study \\
\hline pKS40 & $\mathrm{Carb}^{\mathrm{r}}, \mathrm{Kan}^{\mathrm{r}}, \mathrm{Gent}^{\mathrm{r}}$, pUFR042 fused to pKS27 at EcoRI sites & This study \\
\hline pKS73 & $\mathrm{Carb}^{\mathrm{r}}, \mathrm{Kan}^{\mathrm{r}}, \mathrm{Gent}^{\mathrm{r}}$, pUFR042 fused to pMALc at EcoRI sites & This study \\
\hline pKS59 & $\mathrm{Carb}^{\mathrm{r}}$, Tet $^{\mathrm{r}}$, pJW322 fused to pED32 at EcoRI sites, virB11 gene downstream of virB promoter & This study \\
\hline pCR108 & $\mathrm{Carb}^{\mathrm{r}}$, Tet ${ }^{\mathrm{r}}$, pCR104 fused to pED32 at EcoRI sites, virB11K175A downstream of virB promoter & This study \\
\hline pCR109 & $\mathrm{Carb}^{\mathrm{r}}, \mathrm{Tet}^{\mathrm{r}}$, pCR105 fused to pED32 at EcoRI sites, virB11K175R downstream of virB promoter & This study \\
\hline
\end{tabular}

fractions containing the inner membranes and the fractions containing outer membranes were reapplied to discontinuous sucrose gradients, processed, and assayed as described above.

MBP fusion protein expression and purification. Wild-type MBP-VirB11 fusion protein was purified from the soluble extract of $E$. coli cells and was monitored by SDS-PAGE and staining with Coomassie brilliant blue or by Western blot analysis. The procedure used is as follows. E. coli DH5 $\alpha$ containing pKS27 was grown in 2 liters of $\mathrm{LB}$ broth at $28^{\circ} \mathrm{C}$ to an $\mathrm{OD}_{600}$ of 0.6 , isopropyl$\beta$-D-thiogalactopyranoside (IPTG) was added to $0.5 \mathrm{mM}$, and the cells were grown for an additional $6 \mathrm{~h}$ at $28^{\circ} \mathrm{C}$. Cells were harvested, washed, and lysed as described previously (61). Any insoluble material was removed by centrifugation in an SS34 rotor at $16,000 \times g$ at $4^{\circ} \mathrm{C}$ for $20 \mathrm{~min}$. All further manipulations were performed at $4^{\circ} \mathrm{C}$ unless noted. The proteins in the supernatant (fraction I) were precipitated with $60 \%$ ammonium sulfate (61); the pellet was resuspended in 2.5 $\mathrm{ml}$ of B11 buffer (50 mM Tris- $\mathrm{HCl}[\mathrm{pH} 8], 50 \mathrm{mM} \mathrm{NaCl}, 5 \mathrm{mM} \mathrm{MgCl} \mathrm{M}_{2}, 1 \mathrm{mM}$ dithiothreitol, $0.1 \mathrm{mM}$ phenylmethylsulfonyl fluoride, $0.0019 \%$ Triton $\mathrm{X}-100$, $10 \%$ glycerol) and dialyzed against B11 buffer (fraction II). The dialyzed material was applied to a 15-ml Affi-Gel heparin agarose column (Bio-Rad) equilibrated with B11 buffer. The flowthrough which contained the fusion protein (fraction III) was then applied to a 15-ml amylose resin column (New England Biolabs) equilibrated with B11 buffer. The column was washed with 2 column volumes of B11 buffer, then 5 column volumes of B11 buffer containing $250 \mathrm{mM} \mathrm{NaCl}$, and then 2 column volumes of B11 buffer. Protein was then eluted with B11 buffer containing $10 \mathrm{mM}$ maltose. Fractions containing protein were pooled and concentrated in Centricon 10 microconcentrators. The concentrated protein solution $(<10 \mathrm{ml})$ was dialyzed against $\mathrm{B} 11$ buffer containing $50 \mathrm{mM}$ Tris- $\mathrm{HCl}(\mathrm{pH} 7.4)$ at $4^{\circ} \mathrm{C}$ (fraction IV). To remove contaminating ATPase activity, fraction IV protein was applied to a 1-ml fast protein liquid chromatography (FPLC) Mono Q HR 5/5 column (Pharmacia Biotech, Alameda, Calif.) equilibrated with B11 buffer containing $50 \mathrm{mM}$ Tris- $\mathrm{HCl}(\mathrm{pH} 7.4)$. The column was eluted with a 40-ml gradient of $\mathrm{B} 11$ buffer containing $50 \mathrm{mM}$ Tris- $\mathrm{HCl}(\mathrm{pH} 7.4)$ from 50 to $400 \mathrm{mM}$ $\mathrm{NaCl}$. The fractions were analyzed for the presence of the fusion protein. The fractions were placed at $0^{\circ} \mathrm{C}$ and then analyzed for contaminating ATPase activities, using the native gel system described below. ATPase activity which did not correspond to the MBP-VirB11 fusion protein as measured by using the native gel system described below and parallel Western analysis using antiVirB11 antisera was considered to be contaminating ATPase activity. Fractions containing fusion protein free of contaminating ATPases were pooled (fraction V). By Western analysis, fraction V MBP-VirB11 protein still contained a small amount of DnaK protein. To remove DnaK, a portion of the fraction V sample was brought to $2 \mathrm{mM}$ in ATP and applied to a 1-ml amylose column. The column was washed and eluted as described above. The elution fractions, free of DnaK by Western analysis, were pooled and concentrated by the Centricon microconcentrators and dialyzed as described above. MBP- $\beta$-galactosidase $(\beta-\mathrm{Gal})$ fusion protein (purified from $E$. coli containing pMALc) was purified by using the same procedure.

ATPase and autophosphorylation assays. Protein fractions were tested for ATPase activity on native gels, using the method of Koronakis et al. (29). Briefly, $7 \mu \mathrm{g}$ of protein was electrophoresed on $7 \%$ acrylamide gels in $25 \mathrm{mM}$ Tris-190 $\mathrm{mM}$ glycine buffer. The gels were incubated in $50 \mathrm{mM}$ Tris- $\mathrm{HCl}(\mathrm{pH} 7.8)-10 \mathrm{mM}$ $\mathrm{MgCl}_{2}-1 \mathrm{mM}$ dithiothreitol-2 $\mathrm{mM}$ ATP- $10 \%$ glycerol for $60 \mathrm{~min}$ at $37^{\circ} \mathrm{C}$. The gels were then stained with $0.034 \%$ malachite green, $0.1 \%$ Triton $\mathrm{X}-100$, and 10.5 $\mathrm{g}$ of ammonium molybdate per liter in $1 \mathrm{M} \mathrm{HCl}$, which results in a precipitate in the presence of $\mathrm{P}_{\mathrm{i}}(29)$. Parallel gels were stained with Coomassie brilliant blue or blotted and probed by Western analysis to determine the position of the MBP fusion proteins.

The purified fusion proteins were assayed for ATPase activity over a range of $\mathrm{pH}$ values, using different buffering conditions in the presence of $5 \mathrm{mM} \mathrm{MgCl} \mathrm{Mg}_{2}$ 

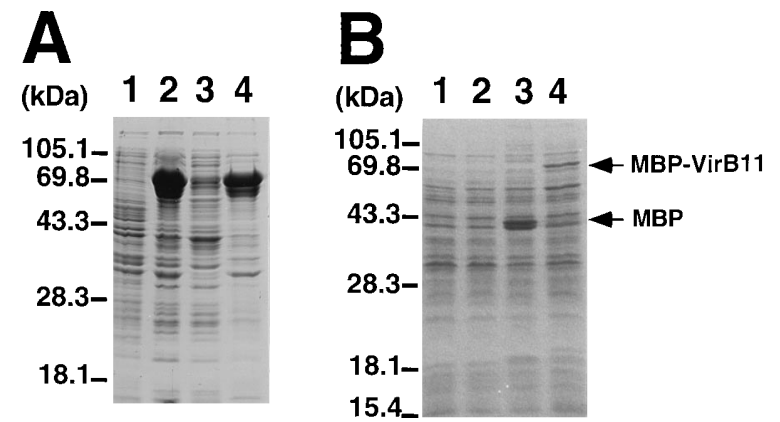

FIG. 1. Expression of MBP-VirB11 in E. coli or A. tumefaciens. (A) Coomassie blue-stained gel showing that the majority of MBP-VirB11 fusion protein is insoluble in E. coli. E. coli $\mathrm{DH} 5 \alpha(\mathrm{pKS} 27)$ was grown for $6 \mathrm{~h}$ in the absence (lane 1) or presence (lane 2) of $0.5 \mathrm{mM}$ IPTG, and the induced cells were lysed and separated into soluble (lane 3) and insoluble (lane 4) fractions (see Materials and Methods). Total protein from cells $\left(1 \mathrm{ml}, \mathrm{OD}_{600}=0.1\right)$ was resolved on an SDS-12.5\% polyacrylamide gel. (B) Coomassie blue-stained gel demonstrating that MBP and MBP-VirB11 are expressed in A. tumefaciens. A. tumefaciens was grown in $\mathrm{MG} / \mathrm{L}$ in the presence of $0.5 \mathrm{mM}$ IPTG. Total protein from A348 (a wild-type strain; lane 1), A10011 (a $\Delta$ virB11 strain; lane 2), A10011(pKS73) (expressing MBP- $\beta-G a l$; lane 3 ), and A10011(pKS40) (expressing MBP-VirB11; lane 4) from equivalent cell volumes $\left(1 \mathrm{ml}, \mathrm{OD}_{600}=0.1\right)$ was resolved on an SDS-12.5\% polyacrylamide gel. The arrows indicate the positions of MBP and MBP-VirB11.

or $5 \mathrm{mM} \mathrm{CaCl} 2$ and a range of ATP concentrations $(10 \mu \mathrm{M}$ to $2 \mathrm{mM})$. ATP hydrolysis was measured by a colorimetric method (56) or by adding $\left[\alpha-{ }^{32} \mathrm{P}\right] \mathrm{ATP}$ or $\left[\gamma^{-32} \mathrm{P}\right] \mathrm{ATP}(>3,000 \mathrm{Ci} / \mathrm{mmol})$ to $60 \mu \mathrm{Ci} / \mu \mathrm{mol}$ and resolving the products on thin-layer chromatography plates (12).

Autophosphorylation assays were performed essentially as described previously (12). Four micrograms of protein was incubated in $50 \mathrm{mM}$ MOPS-KOH $(\mathrm{pH} 6.5)-5 \mathrm{mM} \mathrm{MgCl} 2-1 \mu \mathrm{M}$ ATP $-20 \mu \mathrm{Ci}$ of $\left[\gamma_{-}{ }^{32} \mathrm{P}\right] \mathrm{ATP}(>3,000 \mathrm{Ci} / \mathrm{mmol})$ or $\left[\alpha-{ }^{32} \mathrm{P}\right] \mathrm{ATP}(>3,000 \mathrm{Ci} / \mathrm{mmol})-10 \%$ glycerol in $20 \mu \mathrm{l}$ at $28^{\circ} \mathrm{C}$ for $30 \mathrm{~min}$. Reactions were stopped by adding unlabeled ATP to $2 \mathrm{mM}$. The proteins were separated on SDS-12.5\% polyacrylamide gels and blotted to nitrocellulose, and the filters were exposed to film.

Nucleotide-binding assay. Nucleotide-binding activity of the fusion proteins was measured by using the fluorescent ATP analog TNP-ATP (22) as described previously (28).

Virulence assays. Strains of $A$. tumefaciens were assayed for virulence on Kalanchöe diagremontiana by inoculating $10 \mu \mathrm{l}$ of bacteria on three consecutive leaves of young plants which had been uniformly wounded (11). Bacteria were diluted into sterile $\mathrm{H}_{2} \mathrm{O}$ such that $10 \mu \mathrm{l}$ contained $\sim 10^{8} \mathrm{CFU}$ (no dilution). The bacteria were either undiluted or diluted $10^{-3}$ and $10^{-5}$. Tumors were photographed $\sim 4$ weeks after inoculation.

Other techniques. Concentrations of fusion proteins were determined by using the Bio-Rad protein assay kit, with bovine serum albumin (BSA) as a standard. The concentration of the subcellular fractions was determined by using the Markwell modification of the Lowry assay, with BSA as a standard, as described elsewhere (37). Radioactivity was detected by exposure to film (X-Omat AR; Eastman Kodak Co., Rochester, N.Y.) or scanned with a PhosphorImager and quantitated with ImageQuant data analysis software (Molecular Dynamics).

\section{RESULTS}

Fusion of virB11 to malE. In E. coli, all VirB11 protein is sequestered into inclusion bodies; therefore, during purification, the protein must be denatured and renatured in order to remove VirB11 from the inclusion bodies (12). To study the activities of VirB11 under conditions which would not require such harsh treatment, we developed a scheme to purify soluble VirB11 protein. To this end, the virB11 gene was first cloned into the pMALc expression vector. This vector was chosen because the malE gene is placed downstream of the powerful tac promoter, and the fusion of malE to virB11 facilitates purification of VirB11 (36). The virB11 gene was cloned into pMALc (pKS27) such that the fifth amino acid of VirB11 (339 amino acids) was fused to the four-amino-acid factor Xa cleavage site at the C-terminal end of MBP. This fusion protein has a deduced molecular mass of $80 \mathrm{kDa}$. The malE gene in

\section{Dilution} $110^{-3} 10^{-5}$

A348
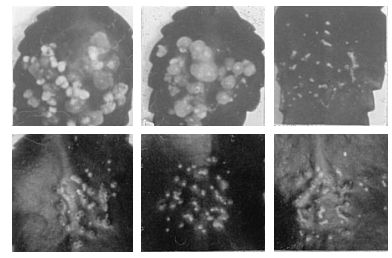

A10011(pKS73) malE

\section{A10011(pKS40) malE-virB11}

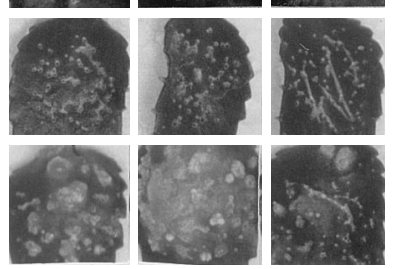

FIG. 2. Expression of MBP-VirB11 can restore virulence to the $\Delta$ virB11 $A$. tumefaciens strain. Leaves of $K$. diagremontiana were wounded and inoculated with undiluted or $10^{-3}$ or $10^{-5}$ dilutions of bacterial cultures grown in MG/L (see Materials and Methods). Leaves were inoculated with strains A348 (wild type), A10011 ( $\Delta$ virB11), A10011(pKS73) (expressing MBP- $\beta-G a l)$, and A10011(pKS40) (expressing MBP-VirB11)

pMALc lacks the codons for amino acids 2 to 26 of the Nterminal end, which encodes the signal sequence. Accordingly, the protein expressed by the gene is located in the cytoplasm. IPTG-induced $E$. coli DH5 $\alpha$ carrying pKS27 overexpressed a protein (Fig. 1A, lane 2) with an apparent molecular mass of 72 $\mathrm{kDa}$ (data not shown). This protein was not seen in uninduced cells (Fig. 1A, lane 1). The 72-kDa protein reacted with both anti-MBP antisera and anti-VirB11 antisera (data not shown). Therefore, we conclude that the $72-\mathrm{kDa}$ protein is the malEvirB11 fusion gene product.

Expression of fusion proteins in $A$. tumefaciens. The genes for the fusion proteins (malE-lac $Z \alpha$ and malE-virB11) were expressed in A. tumefaciens to determine whether the MBPVirB11 fusion protein can function in vivo. To do this, both genes were fused to broad-host-range plasmid pUFR042 (16) and introduced into A. tumefaciens A10011 (AvirB11). The fusion proteins could be detected in whole cells grown in the presence or absence of IPTG when the proteins were analyzed by SDS-PAGE and stained with Coomassie brilliant blue dye (Fig. 1B and data not shown). MBP-VirB11 expressed in $A$. tumefaciens also has an apparent molecular mass of $72 \mathrm{kDa}$ (Fig. 1B, lane 4). Expression of malE-lac $Z \alpha$ generated a protein with an apparent molecular mass of $42 \mathrm{kDa}$, the size expected for MBP with the $\beta-$ Gal fragment removed (Fig. 1B, lane 3).

Since VirB11 is required for virulence of $A$. tumefaciens (12, 54), virB11 deletion strain A10011 expressing MBP or MBPVirB11 was tested for virulence. Strain A10011 expressing MBP-VirB11 was fully virulent on $K$. diagremontiana leaves when assayed at several dilutions (Fig. 2). As expected, MBP could not replace VirB11. Thus, the fusion protein can function as well as VirB11 in tumor formation in A10011, indicating that the MBP portion of the fusion protein does not inhibit the functions of the VirB11 portion in vivo. By Western analysis, we were unable to detect processing of the fusion protein in $A$. tumefaciens that would have resulted in release of native VirB11 (data not shown). Because the fusion protein functions in $A$. tumefaciens in vivo, we went on to purify and study its properties in vitro. 


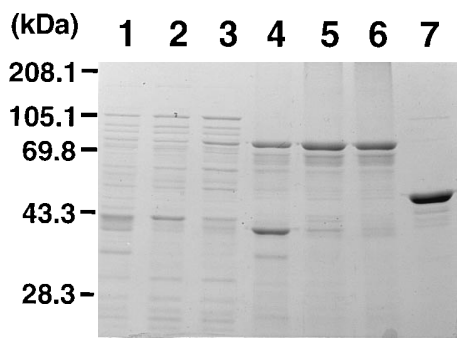

FIG. 3. Purification of MBP-VirB11 protein from 2 liters of E. coli $\mathrm{DH} 5 \alpha(\mathrm{pKS} 27)$ induced for $6 \mathrm{~h}$ in the presence of $0.5 \mathrm{mM}$ IPTG at $28^{\circ} \mathrm{C}$. Equal amounts of protein $(7 \mu \mathrm{g})$ from fractions of the purification were resolved electrophoretically on an SDS- $12.5 \%$ polyacrylamide gel. Lanes: 1 , soluble protein (fraction I; $15 \mathrm{ml}, 32.5 \mathrm{mg} / \mathrm{ml}$ ) after cell lysis; 2, material recovered from $60 \%$ ammonium sulfate precipitation followed by dialysis (fraction II; $5 \mathrm{ml}, 34$ $\mathrm{mg} / \mathrm{ml}$ ); 3, flowthrough fraction (fraction III; $7 \mathrm{ml}, 4.7 \mathrm{mg} / \mathrm{ml}$ ) from a heparin Sepharose column; 4, maltose elution from an amylose resin (fraction IV; $7 \mathrm{ml}$, $0.7 \mathrm{mg} / \mathrm{ml}$ ); 5, MBP-VirB11 protein peak from FPLC Mono Q (fraction V; $3 \mathrm{ml}$, $0.4 \mathrm{mg} / \mathrm{ml}) ; 6$, MBP-VirB11 rechromatographed on the amylose agarose column (fraction VI); 7, MBP- $\beta-$ Gal- $\alpha$ protein from FPLC Mono Q (fraction V; $3 \mathrm{ml}$, $2.6 \mathrm{mg} / \mathrm{ml})$.

Purification of soluble MBP-VirB11 fusion protein from $E$. coli. MBP-VirB11 was purified from induced E. coli $\mathrm{DH} 5 \alpha$ (pKS27) as described in Materials and Methods. Most of the MBP-VirB11 protein remained insoluble after lysis (Fig. 1A, lane 4); however, a small amount of soluble protein was generated (Fig. 1A, lane 3). A gentle lysis procedure was used to remove insoluble protein and nucleic acid (Fig. 3, lane 1). The soluble protein first was concentrated by the addition of ammonium sulfate to $60 \%$ saturation (Fig. 3, lane 2). and then applied to a heparin agarose column. The flowthrough from the heparin agarose column (Fig. 3, lane 3) was fractionated on an amylose column. The maltose-eluted fractions contained the fusion protein (Fig. 3, lane 4).

During purification, fractions were analyzed for ATP-hydrolyzing proteins by staining native gels (see Materials and Methods). The fusion protein, identified by Western analysis, did not have detectable ATPase activity at any stage of the purification (data not shown). However, other ATPase proteins were present, and these were removed by use of ion-exchange chromatography (Fig. 3, lane 5). In addition, DnaK protein copurified with the MBP-VirB11 fusion protein, and this contaminant was removed by addition of ATP to the sample and rechromatography of the proteins on the amylose column (Fig. 3 , lane 6). The remaining protein bands in the final purified preparation all reacted with both anti-VirB11 antisera and anti-MBP antisera and therefore are likely breakdown products of the fusion protein. $\mathrm{MBP}-\beta-\mathrm{Gal}$ fusion protein was purified by the same procedure (Fig. 3, lane 7) and was used as a negative control for the in vitro studies described below.

Activities of MBP-VirB11 fusion protein. VirB11 was shown previously to be an ATPase; however, the level detected was low (turnover number of $1 \mathrm{~min}^{-1}$ ) (12). Therefore, a rigorous study was undertaken to determine if the fusion proteins also had ATPase activity. Purified MBP-VirB11 fusion protein was assayed for ATP-hydrolyzing activity by two different methods (see Materials and Methods). No significant activity was detected for MBP-VirB11 when compared with MBP- $\beta$-Gal over a range of $\mathrm{pH}$ values from 4.9 to 8.5 in the presence of either $\mathrm{Mg}^{2+}$ or $\mathrm{Ca}^{2+}$ (data not shown). Single-stranded DNA, double-stranded DNA, phospholipids, and detergents all failed to stimulate ATPase activity (data not shown). To determine whether the MBP portion of MBP-VirB11 suppresses VirB11 activities, factor $\mathrm{Xa}$, a protease that should cleave MBPVirB11 into MBP and VirB11 moieties, was added to the
ATPase assay. Addition of factor Xa also did not stimulate ATPase activity even though cleavage of approximately $25 \%$ of the protein was observed (data not shown). The fusion proteins also exhibited no GTPase activity (data not shown).

VirB11 protein purified from inclusion bodies exhibits autophosphorylation activity (12). Therefore, the purified fusion proteins were analyzed for autophosphorylation activity with $\left[\gamma-{ }^{32} \mathrm{P}\right] \mathrm{ATP}$ over a range of $\mathrm{pH}$ values from 4.9 to 7.8 . No autophosphorylation activity was seen at any $\mathrm{pH}$ in the presence of $\mathrm{Mg}^{2+}, \mathrm{Ca}^{2+}, \mathrm{Mn}^{2+}$, or $\mathrm{Zn}^{2+}$ (data not shown). Addition of phospholipids did not induce the activity. Factor Xa also did not promote autophosphorylation activity, indicating that the MBP portion of the fusion protein did not inhibit autophosphorylation activity.

Nucleotide binding to the fusion protein was determined by measuring the fluorescence enhancement of the ATP analog TNP-ATP. No fluorescence enhancement was observed over a range of $\mathrm{pH}$ values from 6.2 to 8.5 , suggesting that the protein does not bind to nucleotides (data not shown).

Generation of virB11 mutants. Although nucleotide binding to the fusion protein could not be detected, the predicted amino acid sequence of VirB11 contains a conserved sequence (GPTGSGKT) which corresponds to the Walker box A nucleotide-binding site (GxxGxGKT/S) in many ATP-binding proteins (63). The amino acids of this conserved region have been shown to be important for binding nucleotides in these proteins by nuclear magnetic resonance (17-19), X-ray crystallography $(24,55,69)$, and genetic $(23,49,60)$ studies. The highly conserved lysine is thought to function by interacting with the $\gamma$-phosphate of ATP $(17-19,55,69)$, and changes at this position greatly reduce nucleotide binding $(5,23,46,48,52,60)$. To explore whether this nucleotide-binding site is important in virulence, the virB11 gene was modified by oligonucleotidedirected mutagenesis to inactivate the Walker nucleotide-binding site. The codon for the conserved lysine at position 175 box of virB11 was changed to code for either alanine (K175A) or arginine (K175R).

Biological activities of virB11 mutants. To determine if the virB11 mutants were virulent, the wild-type and the two mutant genes were cloned downstream of the virB promoter and then expressed in a $\Delta$ virB11 strain of $A$. tumefaciens on low-copynumber plasmids (Fig. 4). Cells of $A$. tumefaciens expressing wild-type or mutant virB11 genes were inoculated onto wounded $K$. diagremontiana leaves. The wild-type virB11 gene (pKS59) restored full virulence to $\Delta$ virB11 A. tumefaciens (Fig. 4A). However, the virB11 gene K175A (pCR108) could not complement the virB11 deletion (Fig. 4D). The virB11 gene K175R (pCR109) partially restored virulence (Fig. 4E), since it induced a few small tumors at the higher inoculum levels but no tumors at the highest dilution of the inoculum. The vector pED32 could not restore virulence to the virB11 deletion strain (data not shown). We conclude that an intact Walker box sequence in virB11 is necessary for full virulence of $A$. tumefaciens. However, we could not exclude the possibility that the mutant VirB11 proteins expressed in these strains were unstable or expressed at a low level.

To investigate these possibilities, Western blot analysis was performed to determine whether the strains noted above were synthesizing VirB11 protein. Wild-type and mutant strains were induced with acetylsyringone and monosaccharides and analyzed for expression of VirB11 protein. No VirB11 protein was detected in the virB11 deletion strain with or without the vector pED32 (Fig. 5, lanes 1 and 2). However, VirB11 was detected in the wild-type strain at the expected molecular mass of $38 \mathrm{kDa}$ (Fig. 5, lane 3). Isolates of the virB11 deletion strain with plasmids carrying the wild-type virB11 gene or each of the 


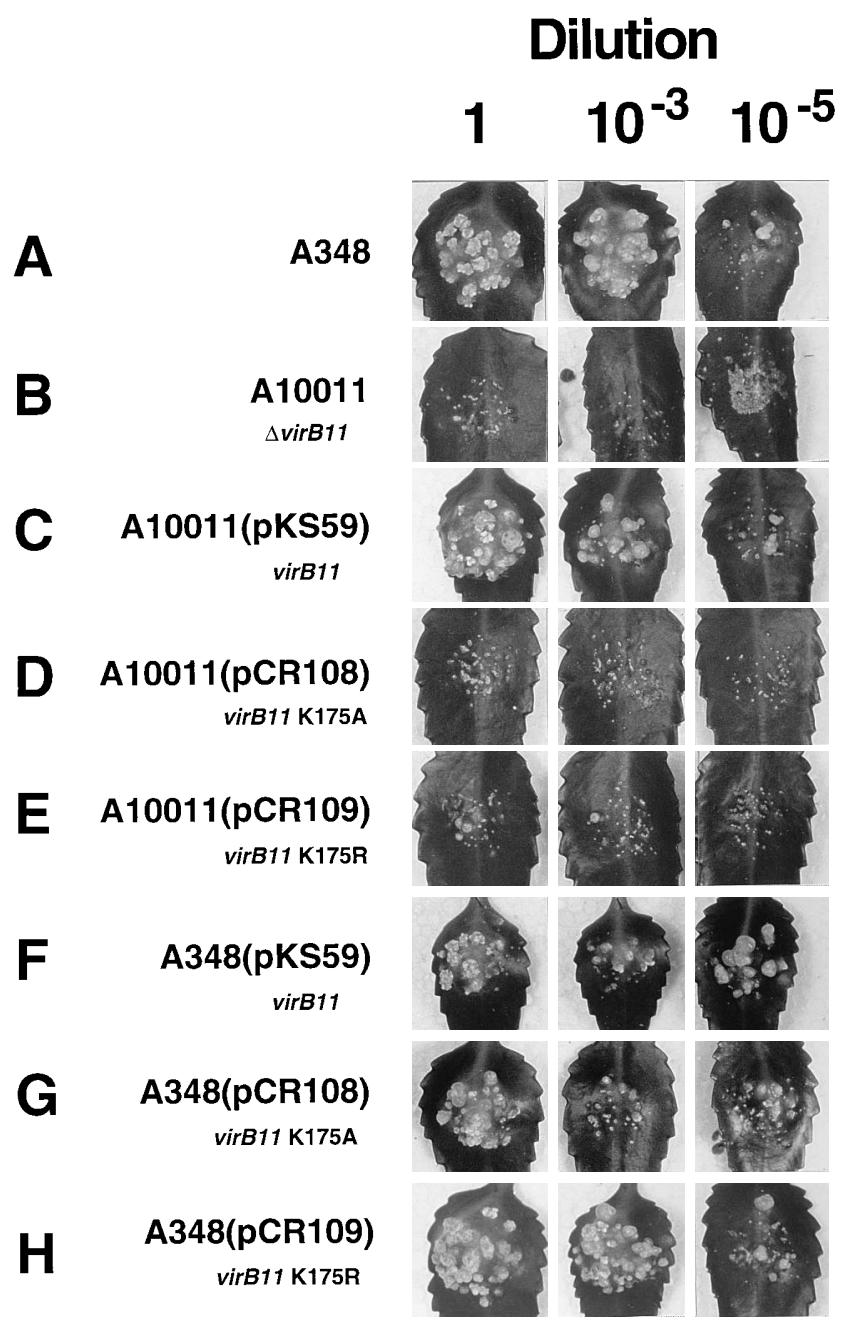

FIG. 4. Virulence assay of strain A10011 ( $\Delta$ virB11) expressing wild-type or mutant virB11 genes in trans. Strains were diluted and inoculated onto uniformly wounded $K$. diagremontiana leaves as for Fig. 3 . Strains of $A$. tumefaciens, some expressing wild-type virB11 or virB11 genes containing the alanine or arginine mutations, were inoculated as indicated at the left.

mutant virB11 genes contained VirB11 protein at a level approximately three- to fourfold higher than in the wild-type strain (Fig. 5, lanes 4 to 6). Therefore, the inability of these mutant virB11 genes to fully complement the $\Delta$ virB11 strain in tumor formation must be due to changes in the Walker box and not protein instability. We conclude that the conserved lysine residue of the Walker box in virB11 is required for the function of VirB11 in vivo.

Effect of virB11 merodiploids on biological activity. T-DNA transport is thought to be catalyzed by a protein complex composed of virB and virD4 gene products in the membranes of $A$. tumefaciens $(57,65)$. Since VirB11 localizes to the inner membrane, it may function in the protein complex to transfer T-DNA to plant cells $(12,57,64)$. If this is the case, expression of the defective virB11 genes in a wild-type strain may reduce virulence of the strain because the mutant proteins could interfere with or block the function of wild-type transport complexes. To determine if this is the case, wild-type virB11 as well as $\operatorname{vir} B 11 K 175 A$ and $\operatorname{vir} B 11 K 175 R$ were introduced into the wild-type strain. The mutant genes did not affect tumor formation in trans (Fig. 4F to $\mathrm{H}$ ), even though the VirB11 protein

\section{$123 \quad 34556$}

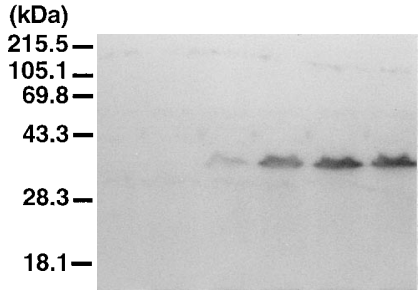

FIG. 5. Detection of expression of wild-type and mutant virB11 alleles in strain A10011 by Western analysis. VirB11 was detected with ${ }^{125}$ I-labeled protein A (see Materials and Methods). Total protein from A10011 (a $\Delta$ virB11 strain lane 1), A10011(pED32) (a vector control; lane 2), A348 (lane 3), A10011 (pKS59) (expressing wild-type in trans; lane 4), A10011(pCR108) (expressing virB11 with an alanine codon at position at 175 in trans; lane 5), and A10011 (pCR109) (expressing virB11 with an arginine codon at position 175 in trans; lane 6) were resolved on an SDS-12.5\% polyacrylamide gel. Radioactivity corresponding to VirB11 protein was quantitated on the PhosphorImager and normalized to the value for A348. Relative radioactivities: lane 1, >0.02; lane 2, $>0.02$; lane 3, 1; lane 4, 3.3; lane 5, 3.7; lane 6, 3.6.

was present at levels more than threefold higher than found in wild-type $A$. tumefaciens by Western blot analysis (data not shown).

Localization of mutant VirB11 protein and fusion proteins in A. tumefaciens. It is conceivable that the mutant VirB11 proteins no longer function in virulence because they are not properly localized to the membrane. The virB11 mutant genes may encode proteins that are no longer directed to the inner membrane because they can no longer interact with a membrane protein or the lipid bilayer. To explore this possibility, subcellular fractions from induced $A$. tumefaciens cells were separated, and the localization of VirB11K175A and VirB11K175R mutant proteins was compared with that of VirB11 by Western blot analysis (Fig. 6A). These data confirm that the VirB11 protein is localized to the inner membrane in a wild-type strain, with a slight amount detected in the outer membrane $(12,57)$ (Fig. 6A, lanes 2 and 3). No VirB11 was detected in the fractions of the $\Delta$ virB11 strain or in the cytoplasmic fraction of the wild-type strain (Fig. 6A, lanes 1, 4, 5, and 6). The $\Delta v i r B 11$ strain expressing wild-type VirB11, VirB11K175A, or VirB11K175R showed the same membrane localization pattern as the wild-type strain A348 (Fig. 6A). The majority of the VirB11 localized to the inner membrane, with some protein cofractionating with the outer membrane (12, 57). However, the amount of VirB11K175R protein recovered after lysis and subcellular fractionation was quite low compared with the amount detected in whole cells (Fig. 5, lane 6, and data not shown). This result suggests that the arginine mutant VirB11 protein is unstable after lysis of the cells. Addition of phenylmethylsulfonyl fluoride (a protease inhibitor) to the fractionation buffers did not protect this mutant protein from degradation (data not shown).

While the MBP-VirB11 protein could complement a virB11 deletion mutation and restore virulence, it was not known whether the presence of the MBP moiety would interfere with its membrane localization. The localization of MBP-VirB11 in A. tumefaciens was explored to determine if the fusion protein was acting in the cytoplasm or could still associate with the membrane. Strain A10011 ( $\Delta$ virB11) expressing the malEvirB11 fusion gene was induced, and the subcellular components were fractionated and blotted as described above (Fig. $6 \mathrm{~B})$. The fusion protein was detected in the cytoplasmic, inner membrane, and outer membrane fractions (Fig. 6B, lanes 7 to and 9), with most of MBP-VirB11 in the inner membrane. The fusion protein appears to be less stable than the wild-type 
A

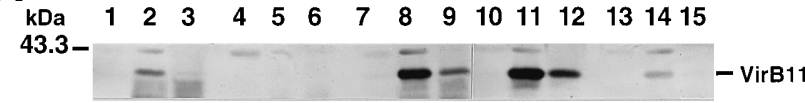

B

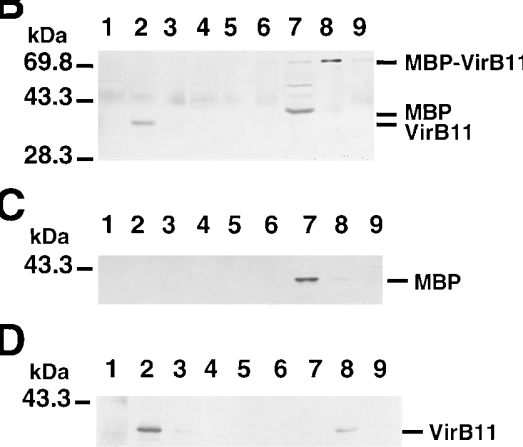

FIG. 6. Wild-type and mutant VirB11 proteins are directed to the inner membrane in $A$. tumefaciens. (A) Western analysis of subcellular fractions from wild-type and mutant $A$. tumefaciens strains. Ten micrograms of protein from cytoplasmic fractions (lanes 1, 4, 7, 10, and 13), inner membrane fractions (lanes $2,5,8,11$, and 14), and outer membrane fractions (lanes 3,6,9,12, and 15) was analyzed from strains A348 (lanes 1 to 3), A10011 ( $\Delta$ virB11; lanes 4 to 6), A10011 (pKS59) (wild-type virB11; lanes 7 to 9), A10011(pCR108) (virB11K175A; lanes 10 to 12), and A10011(pCR109) (virB11K175R; lanes 13 to 15). Proteins were blotted and probed with anti-VirB11 antisera. (B and C) Western analysis of subcellular fractions from $A$. tumefaciens strains expressing MBP-VirB11 or MBP. Ten micrograms of protein from cytoplasmic fractions (lanes 1, 4, and 7), inner membrane fractions (lanes 2, 5, and 8), and outer membrane fractions (lanes 3, 6, and 9) was resolved on SDS-12.5\% polyacrylamide gels. Fractions from strains A348 (lanes 1 to 3), A10011 ( $\Delta$ virB11; lanes 4 to 6), and A10011 (pKS40) (expressing MBP-VirB11; lanes 7 to 9) were probed with anti-VirB11 antisera (B). Fractions from strains A348 (lanes 1 to 3), A10011 (lanes 4 to 6), and A10011(pKS73) (expressing MBP; lanes 7 to 9) were probed with anti-MBP antisera (C). (D) Subcellular localization of VirB11 in a Ti plasmidless strain of A. tumefaciens. Ten micrograms of protein from cytoplasmic fractions (lanes 1, 4, and 7), inner membrane fractions (lanes 2, 5, and 8), and outer membrane fractions (lanes 3, 6, and 9) was resolved on an SDS-12.5\% polyacrylamide gel. Fractions from strains A348 (wild type; lanes 1 to 3), A136(pIB100) (Ti plasmidless, expressing virA and virG; lanes 4 to 6), and A136(pIB100, pED11) (Ti plasmidless, expressing virA, virG, and virB11; lanes 7 to 9) were probed with anti-VirB11 antisera.

protein in $A$. tumefaciens, with the breakdown products (all larger than native VirB11) present in the cytoplasm (Fig. 6B, lane 7). The band of approximately $42 \mathrm{kDa}$ in the cytoplasmic fraction is most likely MBP because it reacts with MBP antisera (data not shown). Thus, we conclude that MBP-VirB11 contains sequences that direct its localization to the inner membrane of $A$. tumefaciens.

To rule out the possibility that the MBP portion of MBPVirB11 directs this membrane localization, the localization of MBP was determined in $A$. tumefaciens. The malE gene in this fusion lacks its $\mathrm{N}$-terminal export signal and in $E$. coli fails to direct the localization of the protein to the periplasm. MBP was localized to the cytoplasm in strain A10011 ( $\Delta$ virB11) expressing MBP, as expected (Fig. 6C, lane 7). A very small amount of MBP was associated with the inner membrane (Fig. $6 \mathrm{C}$, lane 8), but this could be washed from the inner membrane fraction with $0.1 \mathrm{M} \mathrm{NaCl}$ (data not shown). However, MBPVirB11 still remained associated with the inner membrane after washing with $0.1 \mathrm{M} \mathrm{NaCl}$ (data not shown). No MBP protein was detected in A348 or A10011 subcellular fractions (Fig. 6C, lanes 1 to 6). From these data, we conclude that VirB11 contains sequences that direct its localization to the membrane fraction of $A$. tumefaciens and that these sequences still function when MBP is fused to the $\mathrm{N}$-terminal domain of VirB11.
The amino acid sequence of VirB11 does not contain the $\mathrm{N}$-terminal export sequence, nor does it have extensive hydrophobic domains which could be membrane-spanning regions $(12,57,65,73)$. VirB11 may be associated with a protein in the inner membrane which is responsible for its localization. To determine whether VirB11 interacts with any virB-encoded or other Ti plasmid-encoded membrane proteins, the localization of VirB11 in a Ti plasmidless strain was determined. The Ti plasmidless strain A136 carrying a plasmid which contains the virA and virG genes, as well as a plasmid which contains virB11 under control of the virB promoter, was induced, and subcellular fractions were prepared and analyzed as described above. VirB11 protein was detected in the inner membrane of the Ti plasmidless strain expressing virA, virG, and virB11 (Fig. 6D, lane 8) and the wild-type strain (Fig. 6D, lane 2). VirB11 could be interacting with VirA or a chromosomally encoded protein in the membrane, but the association must be extremely tight because VirB11 could not be extracted from the inner membrane fraction by addition of high salt or urea (data not shown), treatments which should disrupt protein-protein interactions. These data suggest that amino acids in VirB11 protein associate directly with the membrane to determine its subcellular localization.

\section{DISCUSSION}

Despite numerous studies on the mechanism by which $A$. tumefaciens transforms plant cells, the transport of T-DNA molecules from the bacterium into the plant cell remains one of the most poorly understood steps in the process $(26,73)$. The induced $A$. tumefaciens cells express the vir genes and produce single-stranded T-DNA molecules, the putative intermediate in T-DNA transfer. However, these molecules are not detected in supernatants of induced cultures, nor is the VirE2 protein, the single-stranded-DNA-binding protein (10a). This finding suggests that T-DNA transfer is a highly regulated process which requires a recipient cell. In this respect, T-DNA transfer is similar to bacterial conjugation (72). Bacterial plasmids are mobilized only after a mating pair has formed between the donor and the recipient cell. By generating mutant virB11 genes and purifying mutant and wild-type VirB11 proteins, we have studied the possible roles of VirB11, a protein indispensable for T-DNA transfer.

Using a fusion vector system, we have purified MBP-VirB11 fusion protein from the soluble fraction of $E$. coli. This fusion protein has an apparent molecular weight that is $10 \%$ less than the predicted molecular weight, but this discrepancy has also been observed with MBP fusions to paramyosin and $\beta-G a l$ (36). MBP fusions have been used successfully to study many different proteins, and in fact, properties of proteins have been measured in vitro with these fusion proteins $(28,33,34,38)$.

The fusion protein was first expressed in A. tumefaciens to determine whether MBP-VirB11 functioned in vivo. Expression of the malE-virB11 gene restored virulence to the virB11 deletion strain of $A$. tumefaciens, indicating that it functioned in vivo. VirB11 localizes to the inner membrane in $A$. tumefaciens. Therefore, the localization of the fusion protein in $A$. tumefaciens was examined to determine whether the MBP moiety could interfere with VirB11 localization. The fusion protein also localized to the inner membrane, indicating that the MBP moiety did not change the localization of the VirB11 protein. This result also indicates that the localization of VirB11 is not determined by a signal sequence at its $\mathrm{N}$-terminal end but is most likely determined by an internal amino acid sequence. Since the intact MBP-VirB11 fusion protein functioned in $A$. tumefaciens in place of native VirB11 and localized properly to 
the membrane, we believe that its properties in vitro reflect the properties of the native protein.

The wild-type MBP-VirB11 protein was purified from a soluble extract of $E$. coli by using procedures that eliminated contaminating ATPases. The purified protein had no ATPase, autophosphorylation, or nucleotide-binding activities. Some of the same results were obtained with PulE (44), a protein that shares $26 \%$ amino acid identity with VirB11 protein (43). PulE protein could not be labeled with azido-ATP in crude extracts of $E$. coli at pH 7.4 (44).

In an earlier study, a low level of ATPase activity was measured with VirB11 protein purified from inclusion bodies in $E$. coli (12). It is conceivable that the putative autophosphorylation activity observed results from the trapping of an intermediate in the ATP hydrolysis reaction rather than from a true autophosphorylation activity. Perhaps the denaturation-renaturation procedure performed by Christie et al. (12) to solubilize the protein allowed the nucleotide-binding domain to refold but did not allow a domain inhibitory to ATPase activity to refold properly. Alternatively, MBP-VirB11, purified from the soluble fraction of $E$. coli, may bind nucleotides only under conditions not yet determined. For example, VirB11 may need to interact with another protein to activate its ATPase activity. There is a precedent for this, and the UvrB protein of E. coli is an example. UvrB contains a Walker box in its amino acid sequence, but no ATPase activity has been detected in purified full-length UvrB protein (10). A proteolytic peptide of the protein, however, does exhibit ATPase activity, indicating that a domain of the protein inhibits the potential ATPase activity of another domain (10). Additional studies revealed that the UvrB protein forms a complex with the UvrA protein and that UvrA activates UvrB ATPase activity $(40,49)$. This may also be the case with VirB11; however, we have not tested the effect of adding other purified vir gene products on VirB11 ATPase activity.

Nevertheless, our data demonstrate that VirB11 must contain an intact nucleotide-binding site to function in T-DNA transfer. If the conserved lysine of the Walker A box is changed to an alanine, the protein no longer functions in T-DNA transfer even though the protein is expressed at a high level. VirB11K175R protein may be unstable, resulting in the attenuated virulence phenotype exhibited by cells producing this mutant protein. These kinds of changes in other ATPases drastically reduce their nucleotide-binding capabilities $(23,48)$. These results show that the nucleotide-binding site is important for function of the VirB11 protein in vivo. A similar result has been seen for other members of the PulE family of transport proteins. PilB, XcpR, and PulE have all been mutated in the Walker A box. pilB Walker box mutants do not assemble pili, and $x c p R$ Walker box mutants are blocked in toxin A and lipase secretion (60). pulE Walker box mutants are blocked in pullulanase secretion in a reconstituted system in E. coli (44).

VirB11 most likely interacts with other VirB proteins in the inner membrane to function in T-DNA transfer. However, merodiploid strains that overexpress mutant VirB11 proteins in addition to wild-type VirB11 are completely wild type in tumor formation. This contrasts with the case for VirB4 mutants altered in the Walker box sequence. VirB4 mutants expressed in wild-type $A$. tumefaciens cells interfered with TDNA transfer and IncQ plasmid conjugation (7, 20). Also, when genes carrying mutations in the Walker boxes of several related proteins, including PilB, XcpR, and PulE, were expressed in trans to their respective wild-type secretion operons, the resulting strains exhibited greatly reduced secretion or pilin assembly $(44,60)$. Since the VirB11 mutants did not interfere with the wild-type transport apparatus, we might conclude that the mutant proteins cannot interact with the transport apparatus. However, it is conceivable that nucleotide binding by VirB11 is required for productive interaction with the transport complex. Thus, mutant VirB11 proteins unable to bind to nucleotides would not be able to stably interact with the transport apparatus.

The membrane localization of the VirB11 has been proposed to result from the interaction of VirB11 protein with members of the transport apparatus (73). This seems highly unlikely since we show that VirB11 localization is independent of Ti plasmid-encoded proteins. However, the VirB11 protein could be interacting with the VirA protein or a chromosomally encoded protein to direct its localization. It seems unlikely that VirB11 interacts with VirA because mutants which lack both VirA and VirG proteins can be complemented by a constitutive $\operatorname{vir} G$ gene and form tumors on plants $(25,42)$. Therefore, VirB11 protein must interact directly with the membrane, or VirB11 interacts with a yet unknown chromosomally encoded membrane protein which directs its localization to the membrane.

\section{ACKNOWLEDGMENTS}

We thank A. W. Karzai, A. Kimball, and R. McMacken for the gift of anti-DnaK antisera; O. Possot and A. Pugsley for communicating data prior to publication; L. Luong for technical assistance; and J. D. Heath and K. Fullner for critical reading of the manuscript and many helpful suggestions.

This work was supported by Public Health Service grant GM32618$22 \mathrm{~A} 1$ from the National Institutes of Health, and K.M.S. was supported by Plant Biology Postdoctoral Fellowship DCB-9000836 from the National Science Foundation.

\section{REFERENCES}

1. Albright, L. M., M. F. Yanofsky, B. Leroux, D. Q. Ma, and E. W. Nester 1987. Processing of the T-DNA of Agrobacterium tumefaciens generates border nicks and linear, single-stranded T-DNA. J. Bacteriol. 169:10461055

2. Alfano, C., and R. McMacken. 1989. Ordered assembly of nucleoprotein structures at the bacteriophage lambda replication origin during the initiation of DNA replication. J. Biol. Chem. 264:10699-10708.

3. Ankenbauer, R. G., E. A. Best, C. A. Palanca, and E. W. Nester. 1991. Mutants of the Agrobacterium tumefaciens virA gene exhibiting acetosyringone-independent expression of the vir regulon. Mol. Plant-Microbe Interact. 4:400-406.

4. Bally, M., A. Filloux, M. Akrim, G. Ball, A. Lazdunski, and J. Tommassen. 1992. Protein secretion in Pseudomonas aeruginosa: characterization of seven $x c p$ genes and processing of secretory apparatus components by prepilin peptidase. Mol. Microbiol. 6:1121-1131.

5. Barbacid, M. 1987. ras genes. Annu. Rev. Biochem. 56:779-827.

6. Beijersbergen, A., A. Dulk-Ras, R. Schilperoort, and P. Hooykaas. 1992 Conjugative transfer by the virulence system of Agrobacterium tumefaciens. Science 256:1324-1326.

7. Berger, B. R., and P. J. Christie. 1993. The Agrobacterium tumefaciens virB4 gene product is an essential virulence protein requiring an intact nucleoside triphosphate-binding domain. J. Bacteriol. 175:1723-1734.

8. Buchanan-Wollaston, V., J. Passiatore, and F. Cannon. 1987. The $m o b$ and oriT mobilization functions of a bacterial plasmid promote its transfer to plants. Nature (London) 328:172-175.

9. Cangelosi, G. A., E. A. Best, G. Martinetti, and E. W. Nester. 1991. Genetic analysis of Agrobacterium. Methods Enzymol. 204:384-397.

10. Caron, P., and L. Grossman. 1988. Involvement of a cryptic ATPase activity of UvrB and its proteolysis product, UvrB* in DNA repair. Nucleic Acids Res. 16:10891-10902.

10a.Christie, P., S. Machlin, K. Stephens, and E. Nester. Unpublished data.

11. Christie, P. J., J. E. Ward, S. C. Winans, and E. W. Nester. 1988. The Agrobacterium tumefaciens virE2 gene product is a single-stranded-DNAbinding protein that associates with T-DNA. J. Bacteriol. 170:2659-2667.

12. Christie, P. J., J. E. J. Ward, M. P. Gordon, and E. W. Nester. 1989. A gene required for transfer of T-DNA to plants encodes an ATPase with autophosphorylating activity. Proc. Natl. Acad. Sci. USA 86:9677-9681.

13. de Maagd, R. A., and B. Lugtenberg. 1986. Fractionation of Rhizobium leguminosarum cells into outer membrane, cytoplasmic membrane, periplasmic, and cytoplasmic components. J. Bacteriol. 167:1083-1085.

14. De Vos, G., and P. Zambryski. 1989. Expression of Agrobacterium nopaline- 
specific VirD1, VirD2 and VirC1 proteins and their requirement for Tstrand production in E. coli. Mol. Plant-Microbe Interact. 2:43-52.

15. Dums, F., J. M. Dow, and M. J. Daniels. 1991. Structural characterization of protein secretion genes of the bacterial phytopathogen Xanthomonas campestris pathovar campestris: relatedness to secretion systems of other gram-negative bacteria. Mol. Gen. Genet. 229:357-364.

16. Feyter, R. D., Y. Yang, and D. W. Gabriel. 1993. Gene for gene interactions between cotton $R$ genes and Xanthomonas campestris pv malvacearum avr genes. Mol. Plant-Microbe. Interact. 6:225-237.

17. Fry, D. C., S. A. Kuby, and A. S. Mildvan. 1985. NMR studies of the MGATP binding site of adenylate kinase and of a 45-residue peptide fragment of the enzyme. Biochemistry 24:4680-4694.

18. Fry, D. C., S. A. Kuby, and A. S. Mildvan. 1986. ATP-binding site of adenylate kinase: mechanistic implications of its homology with ras-encoded p21, F1-ATPase, and other nucleotide binding proteins. Proc. Natl. Acad. Sci. USA 83:907-911.

19. Fry, D. C., S. A. Kuby, and A. S. Mildvan. 1987. NMR studies of the AMP-binding site and mechanism of adenylate kinase. Biochemistry 26: 1645-1655.

20. Fullner, K. J., K. M. Stephens, and E. W. Nester. An essential virulence protein of Agrobacterium tumefaciens, VirB4, requires an intact mononucleotide binding domain to function in transfer of T-DNA. Mol. Gen. Genet., in press.

21. Garfinkel, D. J., and E. W. Nester. 1980. Agrobacterium tumefaciens mutants affected in crown gall tumorigenesis and octopine catabolism. J. Bacteriol. 144:732-743.

22. Hiratsuka, T. 1982. Biological activities and spectroscopic properties of chromaphoric and fluorescent analogs of adenine nucleoside and nucleotides, 2'-3'-O-(2,4,6-trinitrocyclohexadienylidene) adenosine derivatives. Biochim. Biophys. Acta 719:509-517.

23. Iwamoto, A., M.-Y. Park, M. Maeda, and M. Futai. 1993. Domains near ATP gamma phosphate in the catalytic site of $\mathrm{H}+$-ATPase. J. Biol. Chem. 268: 3156-3160.

24. Jackson, A. P., and A. Maxwell. 1993. Identifying the catalytic residue of the ATPase reaction of DNA gyrase. Proc. Natl. Acad. Sci. USA 90:1123211236.

25. Jin, S., Y. N. Song, S. Q. Pan, and E. W. Nester. 1993. Characterization of a virG mutation that confers constitutive virulence gene expression in Agrobacterium. Mol. Microbiol. 7:555-562.

26. Kado, C. I. 1993. Agrobacterium-mediated transfer and stable incorporation of foreign genes in plants, p. 243-254. In D. B. Clewell (ed.), Bacterial conjugation. Plenum Press, New York.

27. Kitto, G. B. 1969. Intra- and extramitochondrial malate dehydrogenases from chicken and tuna heart. Methods Enzymol. 13:106-116.

28. Ko, Y. H., P. J. Thomas, M. R. Delannoy, and P. L. Pedersen. 1993. The cystic fibrosis transmembrane conductance regulator. J. Biol. Chem. 268: 24330-24338.

29. Koronakis, V., C. Hughes, and E. Koronakis. 1993. ATPase activity and ATP/ADP-induced conformational change in the soluble domain of the bacterial protein translocator HlyB. Mol. Microbiol. 8:1163-1175.

30. Koukolíková-Nicola, Z., D. Raineri, K. Stephens, C. Ramos, B. Tinland, E. W. Nester, and B. Hohn. 1993. Genetic analysis of the virD operon of Agrobacterium tumefaciens: a search for functions involved in transport of T-DNA into the plant cell nucleus and in T-DNA integration. J. Bacteriol. 175:723-731.

31. Kunkel, T. A., J. D. Roberts, and R. A. Zakour. 1987. Rapid and efficient site-specific mutagenesis without phenotypic selection. Methods Enzymol. 154:367-382

32. Laemmli, U. K. 1970. Cleavage of structural proteins during the assembly of the head of bacteriophage T4. Nature (London) 227:680-685.

33. Lee, H.-S., D. K. Berger, and S. Kustu. 1993. Activity of purified NIFA, a transcriptional activator of nitrogen fixation genes. Proc. Natl. Acad. Sci. USA 90:2266-2270.

34. Lee, H.-S., F. Narberhaus, and S. Kustu. 1993. In vitro activity of NifL, a signal transduction protein for biological nitrogen fixation. J. Bacteriol. 175: 7683-7688.

35. Lindeberg, M., and A. Collmer. 1992. Analysis of eight out genes in a cluster required for pectic enzyme secretion by Erwinia chrysanthemi: sequence comparison with secretion genes from other gram-negative bacteria. J. Bacteriol. 174:7385-7397.

36. Maina, C. V., P. D. Riggs, A. G. I. Grandea, B. E. Slatko, L. S. Moran, J. A. Tagliamonte, L. A. McReynolds, and C. Guan. 1988. An Escherichia coli vector to express and purify foreign proteins by fusion to and separation from maltose-binding protein. Gene 74:365-373.

37. Markwell, M. A. K., S. M. Haas, L. L. Bieber, and N. E. Tolbert. 1978. A modification of the Lowry procedure to simplify protein determination in membrane and lipoprotein samples. Anal. Biochem. 87:206-210.

38. Ninfa, E. G., M. R. Atkinson, E. S. Kamberov, and A. Ninfa. 1993. Mechanism of autophosphorylation of Escherichia coli nitrogen fixation regulator II (NRII or NtrB): trans-phosphorylation between subunits. J. Bacteriol. 175: 7024-7032.

39. Nunn, D., S. Bergman, and S. Lory. 1990. Products of three accessory genes,
pilB, pilC, and pilD, are required for biogenesis of Pseudomonas aeruginosa pili. J. Bacteriol. 172:2911-2919.

40. Oh, E. Y., L. Claassen, S. Thiagalingam, S. Mazor, and L. Grossman. 1989. ATPase activity of the UvrA and UvrAB protein complexes of the Escherichia coli UvrABC endonuclease. Nucleic Acids Res. 17:4145-4159.

41. Okamoto, S., Y. A. Toyoda, K. Ito, I. Takebe, and Y. Machida. 1991. Localization and orientation of the VirD4 protein of Agrobacterium tumefaciens in the cell membrane. Mol. Gen. Genet. 228:24-32.

42. Pazour, G. J., C. N. Ta, and A. Das. 1992. Constitutive mutations of Agrobacterium tumefaciens transcriptional activator virG. J. Bacteriol. 174:41694174.

43. Possot, O., C. d'Enfert, I. Reyss, and A. Pugsley. 1992. Pullulanase secretion in Escherichia coli $\mathrm{K}-12$ requires a cytoplasmic protein and a putative polytopic cytoplasmic membrane protein. Mol. Microbiol. 6:95-105.

44. Possot, O., and A. P. Pugsley. 1994. Molecular characterization of PulE, a protein required for pullulanase secretion. Mol. Microbiol. 12:287-299.

45. Pugsley, A. 1993. The complete general secretory pathway in gram-negative bacteria. Microbiol. Rev. 57:50-108.

46. Reinstein, J., M. Brune, and A. Wittinghofer. 1988. Mutations in the nucleotide binding loop of adenylate kinase of Escherichia coli. Biochemistry 27: 4712-4720.

47. Sambrook, J., E. F. Fritsch, and T. Maniatis. 1989. Molecular cloning: a laboratory manual, 2nd ed. Cold Spring Harbor Press, Cold Spring Harbor, N.Y.

48. Seeley, T., and L. Grossman. 1989. Mutations in the Escherichia coli UvrB ATPase motif compromise excision repair capacity. Proc. Natl. Acad. Sci. USA 86:6577-6581.

49. Seeley, T. W., and L. Grossman. 1990. The role of Escherichia coli UvrB in nucleotide excision repair. J. Biol. Chem. 265:7158-7165.

50. Shirasu, K., and C. I. Kado. 1993. Membrane location of the Ti plasmid VirB proteins involved in the biogenesis of a pilin-like conjugative structure on Agrobacterium tumefaciens. FEMS Microbiol. Lett. 111:287-294.

51. Shirasu, K., Z. Koukolikova-Nicola, B. Hohn, and C. Kado. 1994. An innermembrane-associated virulence protein essential for T-DNA transfer from Agrobacterium tumefaciens to plants exhibits ATPase activity and similarities to conjugative transfer genes. Mol. Microbiol. 11:581-588.

52. Sigal, I., J. B. Gibbs, J. S. D'Alonzo, G. L. Temeles, B. S. Wolanski, S. H. Socher, and E. M. Scolnick. 1986. Mutant ras encoded proteins with altered nucleotide binding exert dominant biological effects. Proc. Natl. Acad. Sci. USA 83:952-956.

53. Southern, E. M. 1975. Detection of specific sequences among DNA fragments separated by gel electrophoresis. J. Mol. Biol. 98:503-517.

54. Stachel, S. E., and E. W. Nester. 1986. The genetic and transcriptional organization of the vir region of the A6 Ti plasmid of Agrobacterium tumefaciens. EMBO J. 5:1445-1454.

55. Story, R. M., and T. A. Steitz. 1992. Structure of the RecA protein-ADP complex. Nature (London) 355:374-376.

56. Sumner, J. B. 1944. A method for the colorimetric determination of phosphorus. Science 100:413-414.

57. Thorstenson, Y. R., G. A. Kuldau, and P. C. Zambryski. 1993. Subcellular localization of seven VirB proteins of Agrobacterium tumefaciens: implications for the formation of a T-DNA transport structure. J. Bacteriol. 175: 5233-5241.

58. Thorstenson, Y. R., and P. C. Zambryski. 1994. The essential virulence protein VirB8 localizes to the inner membrane of Agrobacterium tumefaciens. J. Bacteriol. 176:1711-1717.

59. Towbin, H. T., T. Staehelin, and J. Gordon. 1979. Electrophoretic transfer of proteins from polyacrylamide gels to nitrocellulose sheets: procedure and some applications. Proc. Natl. Acad. Sci. USA 76:4350-4354.

60. Turner, L., J. C. Lara, D. N. Nunn, and S. Lory. 1993. Mutations in the consensus ATP-binding sites of XcpR and PilB eliminate extracellular protein secretion and pilus biogenesis in Pseudomonas aeruginosa. J. Bacteriol. 175:4962-4969.

61. Ueda, K., R. McMacken, and A. Kornberg. 1978. DnaB protein of Escherichia coli. Purification and role in the replication of phiX174 DNA. J. Biol. Chem. 253:261-269.

62. Vieira, J., and J. Messing. 1987. Production of single-stranded plasmid DNA. Methods Enzymol. 153:3-11.

63. Walker, J. E., M. Sarste, M. J. Runswick, and N. J. Gay. 1982. Distantly related sequences in the $\alpha$ - and $\beta$-subunits of ATP synthase, myosin, kinases, and other ATP-requiring enzymes and a common nucleotide binding fold. EMBO J. 1:945-951.

64. Ward, J., E. Dale, and A. Binns. 1991. Activity of the Agrobacterium T-DNA transfer machinery is affected by virB gene products. Proc. Natl. Acad. Sci. USA 88:9350-9354

65. Ward, J. E., D. E. Akiyoshi, D. Regier, A. Datta, M. P. Gordon, and E. W. Nester. 1988. Characterization of the virB operon from an Agrobacterium tumefaciens Ti plasmid. J. Biol. Chem. 263:5804-5814.

66. Ward, J. E. J., E. M. Dale, P. J. Christie, E. W. Nester, and A. N. Binns. 1990 Complementation analysis of Agrobacterium tumefaciens $\mathrm{Ti}$ plasmid virB genes by use of a vir promoter expression vector: virB9, virB10, and virB11 are essential virulence genes. J. Bacteriol. 172:5187-5199. 
67. Ward, J. E. J., E. M. Dale, E. W. Nester, and A. N. Binns. 1990. Identification of a VirB10 protein aggregate in the inner membrane of Agrobacterium tumefaciens. J. Bacteriol. 172:5200-5210.

68. Weiss, A. A., F. D. Johnson, and D. L. Burns. 1993. Molecular characterization of an operon required for pertussis toxin secretion. Proc. Natl. Acad. Sci. USA 90:2970-2974.

69. Wigley, D. B., G. J. Davies, E. J. Dodson, and A. Maxwell. 1991. Crystal structure of an N-terminal fragment of the DNA gyrase B protein. Nature (London) 351:624-629.

70. Winans, S. C. 1992. Two-way chemical signalling in Agrobacterium-plant interactions. Microbiol. Rev. 56:12-31.
71. Yanisch-Perron, C., J. Vieira, and J. Messing. 1985. Improved M13 phage cloning vectors and host strains: nucleotide sequences of the M13mp18 and pUC19 vectors. Gene 33:103-119.

72. Zambryski, P., H. M. Goodman, M. M. Van, and J. Schell. 1983. Agrobacterium tumor induction Agrobacterium tumefaciens, p. 505-535. In J. A. Shapiro (ed.), Mobile genetic elements. Academic Press, New York.

73. Zambryski, P. C. 1992 . Chronicles from the Agrobacterium-plant cell DNA transfer story. Annu. Rev. Plant Physiol. 43:465-490.

74. Ziegelin, G., W. Pansegrau, B. Strack, D. Balzer, M. Kroger, V. Kruft, and E. Lanka. 1991. Nucleotide sequence and organization of genes flanking the transfer origin of promiscuous plasmid RP4. DNA Seq. 1:303-327. 